\title{
Estimating the Value of Time and Its Application
}

\author{
Lasmini Ambarwati ${ }^{1}$, Amelia Kusuma Indriastuti ${ }^{2}$, Pretiwindya \\ Kusumawardhani $^{1}$ \\ ${ }^{1}$ Department of Civil Engineering, Faculty of Engineering, Brawijaya \\ University, Indonesia \\ ${ }^{2}$ Department of Civil Engineering, Faculty of Engineering, Diponegoro, \\ Semarang, Indonesia \\ *Corresponding Author: Lasmini Ambarwati: labarwati@ub.ac.id
}

\section{Citation: Ambarwati L., Indriastuti A. K., Kusumawardhani P. (2017) Estimating the Value of Time and Its Application. Open Science Journal 2(1).}

Received: 30 ${ }^{\text {th }}$ August, 2016

Accepted: $17^{\text {th }}$ February, 2017

Published: $21^{\text {st }}$ June, 2017

Copyright:@ 2017 This is an open access article under the terms of the Creative Commons

Attribution License, which permits unrestricted use, distribution, and reproduction in any medium, provided the original author and source are credited.

Funding: The author(s) received no specific funding for this work.

Competing Interests: The author(s) have declared that no competing interests exists.

\begin{abstract}
Values of travel time are essential factors in the design of transport infrastructure. The value of time is used in transport models to monetize travel time related to the socio-economic background of travelers. This paper assesses the estimation of the value of time based on questionnaires distributed to travelers in a preference survey. The mode choice approach is employed to estimate these values dependent on vehicle classes for weekdays and at the weekend. Two of the main conclusions using the mode choice approach are that the value of time for private vehicle users is approximately 1.5 times the value of time for public transport users; and the value of travel time on the weekday is twice that of the weekend. This indicates that public transport passengers have more travel time savings than when they use other modes. Another method, the income approach, arrives at similar values of time as that estimated by the mode choice approach. The willingness to use public transport in weekdays is increasing. As a consequence, public transport should be operated at a higher frequency.
\end{abstract}

Keywords: Value of time, Mode choice approach, Income approach,

Modal split, Travelers' preferences 


\section{Introduction}

In most cities, particularly cities in developing countries, travel time savings is an important issue when formulating transport policy and designing a transport infrastructure.

With the considerable expansion and growth of housing development in suburban areas, it becomes necessary to assess the travel time savings of residents living in these areas. Time saving analysis is intended to support future plans for transport infrastructures and the public transport system in balance with housing development.

The value of time is one of the main factors in estimating the benefits for travelers from an economic perspective. Henser [1] argued that value of time equals the amount of money spent on saving travel time. Value of time has been illustrated in the modeling of traveler behavior and demand forecasts by Wardman [2]. He explained that an individual's willingness to pay for travel time can be estimated from the travel demand model and is an implicit trade-off between time and money. Estimation of the value of time is necessary to determine the social acceptability of the expenditure of scarce public funds. Mackie et al. [3] demonstrated that time is a scarce resource and direct willingness to pay should be weighted to gain social approval for some projects.

According to Tseng and Verhoef [4], individuals' time-related shadow prices indeed vary strongly over the morning peak and values of travel time savings were consequently strongly time-dependent, following plausible and intuitive patterns. This research applied a state preference survey to determine the respondents' departure time choices for the morning commute. Econometrically estimated parameters was used to estimate values of leisure and work in three cities, i.e., Santiago (Chile), Karlsruhe (Germany), and Thurgau (Switzerland) [5]. Empirical analysis of those values revealed that values of leisure were different from the wage rate.

Value of time is a benefit obtained by travelers resulting from time savings after infrastructure development. However, an assessment of the value of time is required in order to improve the performance of the public transport system related to travel time savings for travelers, particularly for those in most cities in Indonesia.

The objective of this paper is to highlight the time taken by individuals, residing in the suburbs due to settlement development in those areas, to travel to the city center using each transport mode on weekdays and at the weekend in a developing country. The second objective is to apply time value savings for improving the public transport system and to employ the value of time in simulating a transport model using OmniTRANS application.

The structure of this paper is organized as follows: We briefly review the methodology used to obtain data by distributing questionnaires to residents in all city zones, particularly those living in the suburbs. We then discuss the parameters influencing the value of time and the application of the value of time in simulating a transport model. Finally, we present our conclusions and recommendations. 


\section{Methodology}

Several factors influence the value of time - travel length, transport mode, time period, trip purpose, and environmental conditions.

By using the mode choice approach and the income approach, we estimate the value of time based on a revealed and stated preference survey. The survey was conducted by distributing questionnaires to residents in the suburbs and travelers going from suburban areas to the city center.

The mode choice approach is represented as follows:

$$
\begin{aligned}
& P_{q}=a_{i}+a_{2}\left(C_{p}-C_{q}\right)+a_{2}\left(T_{p}-T_{q}\right) \\
& \mathrm{VOT}=\lambda=\frac{a_{2}}{a_{1}}
\end{aligned}
$$

where $P_{q}$ is the transport mode choice of $q(\%), C_{p}$ is the travel cost for mode $p$ (IDR-Indonesian Rupiah rate), $C_{q}$ is the travel cost for mode $q$ (IDR), $T_{p}$ is the travel time for mode $p$ (minutes), $T_{q}$ is the travel time for mode $q$ (minutes), $\lambda$ is the value of time (VOT), and $a_{1}, a_{2}$ are parameters.

Comparative analysis was done using the value of time estimated by the income approach:

$\lambda=\frac{\mathrm{GDP} / \text { Person }}{\text { Working time } / \text { Person }}$

where $\lambda$ is the value of travel time and GDP is the gross domestic product of the population.

\section{Data}

Data consist of residents' socio-economic characteristics and trip characteristics, particularly travel time and cost, and trip length for each transport mode. Data was obtained from questionnaires distributed in the 163 zones (Desas) of the city of Surabaya.

The questionnaires were distributed in the 163 zones in proportion to the population size of each zone. The questionnaire comprised three parts: socioeconomic background, trip characteristic, and transport mode choice for weekend and weekday. The first part of the questionnaire focused on educational background, income, and job. The second part related to trip characteristics, such as the reason for the trip, starting point and destination of each trip, transport mode choice, travel time and cost on a weekday, with another part detailing similar questions for travelers at the weekend. The questionnaire was distributed to 554 respondents spread over the163 zones.

\section{Study Area}

In this research, we choose Surabaya City as the case study area. Surabaya is the capital city of East Java Province and comprises 31districts divided into 163 zones, with a total area of $327 \mathrm{~km}^{2}$. It is located at an altitude of $3-6 \mathrm{~m}$ above mean sea level. Surabaya has a population of approximately 2.8 million, with a high density of more than 10,000 persons per $\mathrm{km}^{2}$, which can be identified as a highly urbanized area as seen in Fig. 1 [6]. 


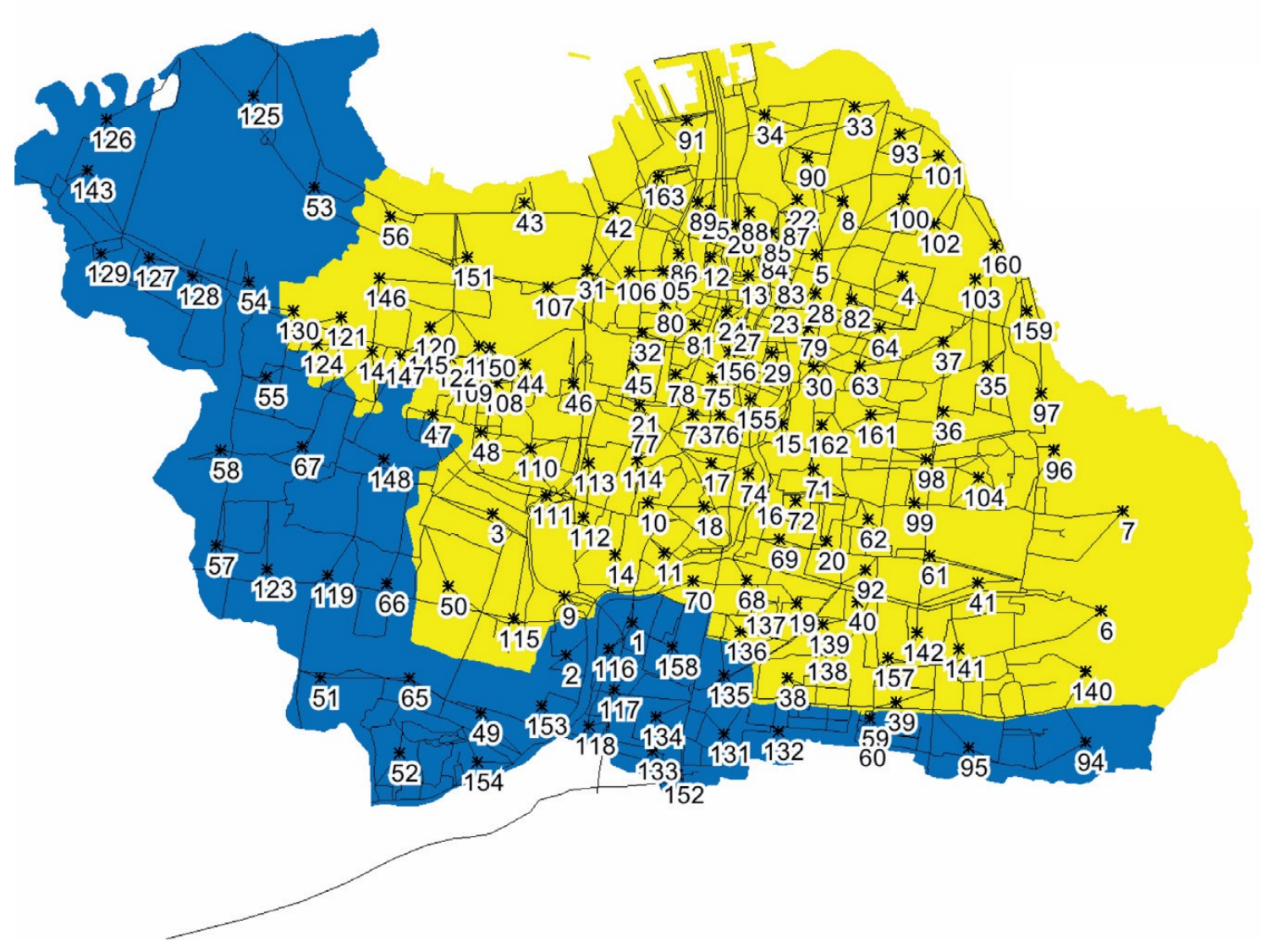

Legend

Areas

Location

- <undefine

Urban

SubUrban

Fig. 1. Map of study area (Surabaya City) in East Java Province, Indonesia.

\section{Results and Discussion}

\section{Comparative Analysis with Empirical Data from Questionnaires}

Details of the socio-economic background of the traveler are required to estimate average income and GDP of the population in each zone. $78 \%$ of respondents have an income of less than 1.5 million rupiahs.

Trip characteristics are based on the fact that most travelers have a motorcycle, which they used for the majority of their trips. As a consequence, traffic volume consists predominantly of motorcycles on all city roads. Trip length covered by $77 \%$ of respondents on weekdays is less than $10 \mathrm{~km}$, while $63 \%$ of respondents take weekend trips less than $10 \mathrm{~km}$. Regarding travel time, most users of motorcycles spend less than 20 minutes on weekday trips, while public transport passengers need 10-30 minutes. Weekday trips show an even distribution in all ranges of travel time for private vehicles and public transport as seen in Fig. 2. 


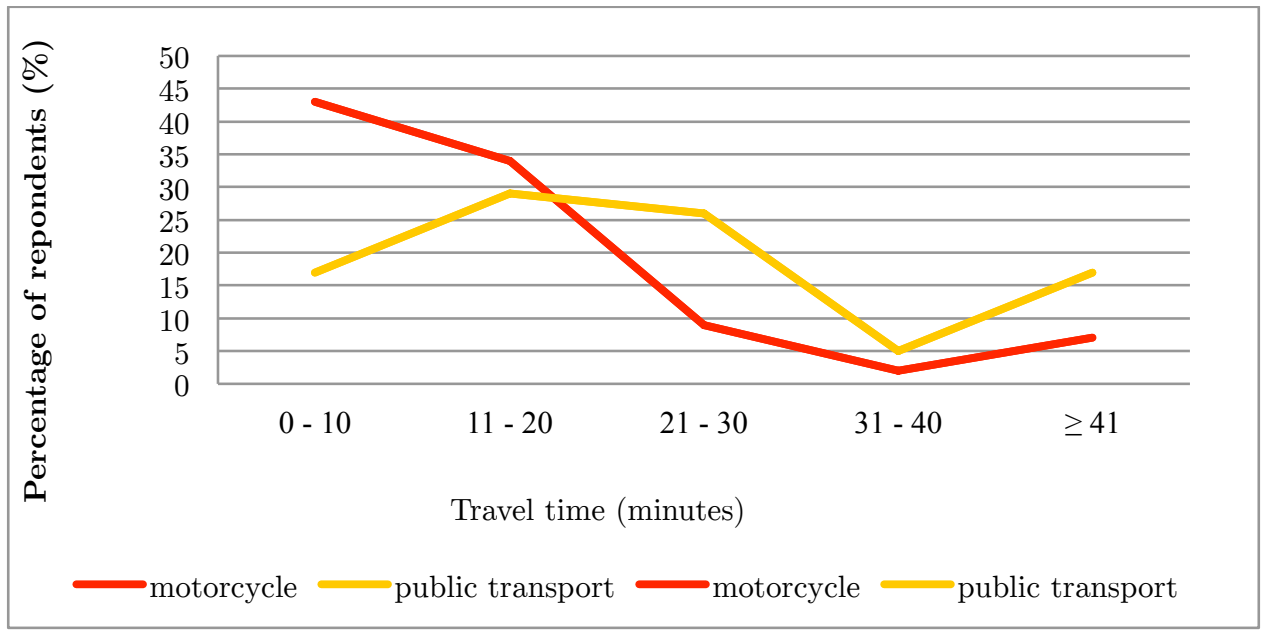

Fig. 2. Trip characteristics for travel time in weekdays.

From the time distribution, it is demonstrated that travel time on weekdays is shorter than at the weekend. Thus, travel time of motorcycles is less than other transport modes (public transport) for weekday and weekend trips.

Mode choice is necessary to identify the type of vehicles which is predominantly in the traffic flow. Most residents use private vehicles, particularly the motorcycle, for weekday and weekend trips as shown in Fig. 3.

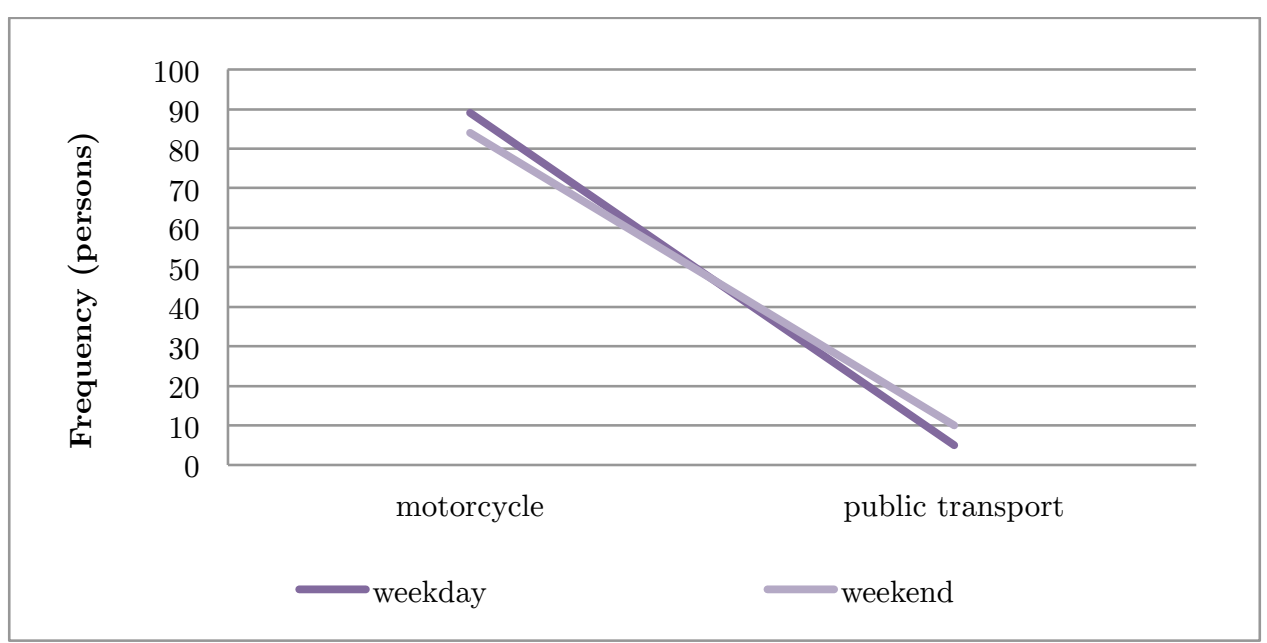

Fig. 3. Mode choice for weekday and weekend trips.

Motorcycles are the preferable mode choice because their use results in the shortest travel time for weekday and weekend trips. Public transport has no fixed schedule, leading to a travel time longer than that of private vehicles.

From the survey, a brief analysis shows that the differences in travel time and cost between private vehicles and public transport influence the mode choice. Transport mode choice is determined for each vehicle class (private vehicle and public transport) based on the differences in travel time and cost by using regression-fit analysis. The parameters, approximated to a linear model, can be used to assess the likelihood of choosing a particular transport mode for weekday and weekend. 
For assessing travel cost in order to calculate value of time, an estimation of travel length, gasoline consumption, and gasoline price is used for each transport mode. Travel cost is calculated using the following equation:

Travel cost $=\frac{\text { Travel length }}{\text { Gasoline consumed }}$. Gasoline price

In further analysis, the travel cost is used to estimate the value of time based on the mode choice approach, as explained in equation (1) and (2). Parameters of value of time are approximated to a multilinear regression model for each transport mode as explained in Table 1.

Table 1. Parameters of value of time in two conditions (weekday and weekend).

\begin{tabular}{|c|c|c|c|c|}
\hline \multirow{2}{*}{ Transport Mode } & $\begin{array}{c}\text { Trip } \\
\text { Characteristics }\end{array}$ & $a_{0}$ & $a_{1}$ & $a_{2}$ \\
\hline \multirow{2}{*}{ Private Vehicle } & Weekday & 0.96 & $-2.1 .10^{-7}$ & $1.15 .10^{-4}$ \\
\cline { 2 - 5 } & Weekend & 0.9 & $1.06 .10^{-6}$ & $3.23 .10^{-4}$ \\
\hline \multirow{2}{*}{ Public Transport } & Weekday & 0.023 & $-1.6 .10^{-7}$ & $6.3 .10^{-4}$ \\
\cline { 2 - 5 } & Weekend & 0.012 & $1.5 .10^{-7}$ & $2.99 .10^{-5}$ \\
\hline
\end{tabular}

From the parameters, we can estimate the value of time $(\lambda)$ for each transport mode for weekday and weekend trips as shown in Table 2.

Table 2. Value of time for each transport mode.

\begin{tabular}{|c|c|c|}
\hline \multirow{2}{*}{ Transport Mode } & Trip Characteristics & $\begin{array}{c}\text { ( } \\
\text { (IDR/ person/hour) }\end{array}$ \\
\hline \multirow{2}{*}{ Private Vehicle } & Weekday & 32.876 \\
\cline { 2 - 3 } & Weekend & 18.220 \\
\hline \multirow{2}{*}{ Public Transport } & Weekday & 23.448 \\
\cline { 2 - 3 } & Weekend & 11.924 \\
\hline
\end{tabular}

Comparative analysis is also conducted by another approach, the income approach, aimed at estimating the value of time from the GDP of all residents in the city of Surabaya. Assuming that the GDP for the city of Surabaya in 2011 was 154.24 million IDR, and the total population was approximately 2,765,908, with an annual total of 1920 hours of work, the value of time is as follows:

$$
\begin{aligned}
& \lambda=\frac{154.240 .000 .000 .000 / 2.765 .908}{1920} \\
& \lambda=\operatorname{Rp} .29 .044(\mathrm{IDR} / \text { hour } / \text { person })
\end{aligned}
$$

By using the income approach, value of time is quite similar to the value of time for private vehicles for a weekday trip. The two approaches have different values due to the difference in variables influencing each approach. The transport mode approach is based on revealed preference survey, a more dynamic response from residents.

From the survey, the income of motorcycle users is higher than the income of public transport passengers. As a result, the value of time of the motorcyclist is greater than the value of travel time of public transport passengers. 
Value of time savings in weekday trips is significantly higher than in weekend trips, due to the number of gains obtained from the trip. The benefits are related to a more efficient use of time and much greater convenience.

\section{Application of Time Value Savings}

The significant difference between the value of time in weekdays and weekends has an effect on the changes in the modal split for the two conditions (weekday and weekend). By simulating the two conditions and using OmniTRANS application model as the transport model, the two conditions give a significant result in the modal split, indicating the percentage of trips for each transport mode type.

Table 3 explains that the modal split of public transport in the weekday is larger than the modal split at the weekend. It means that $16 \%$ of the willingness to use public transport reduces based on time value savings. Public transport passengers prefer a trip in the weekday. The result is in line with the respondents' preferences based on a survey conducted in September 2012. 24\% of respondents chose public transport during weekdays, while the use of public transport is only $19.5 \%$ in the weekend. A significant effect on using cars occurs at weekends. The use of cars increases $6 \%$ in weekends compared to weekdays, due to time saving value at weekends. The reasons to use private vehicles, particularly cars are comfort and safety besides the time saving factor. This was revealed by $70.4 \%$ of respondents in the survey.

Table 3. Modal split for weekdays and weekends.

\begin{tabular}{|c|c|c|}
\hline Transport mode & Weekday & Weekend \\
\hline Public transport & 5.82 & 4.87 \\
\hline Motorcycle & 58.73 & 57.67 \\
\hline Car & 34.88 & 37.04 \\
\hline
\end{tabular}

The number of public transport passengers reduces at weekends, particularly in main roads from the north to the south side of the city, as seen in Fig. 4a and Fig. 4b. The reductions of the public transport load at the weekend result in the increase of the use of cars, particularly in the south and southwest sides of the city, as illustrated in Fig. 4e and Fig. 4f. Figures 4c and 4d explain that the number of motorcycles does not significantly decrease at the weekend compared to the weekdays. 


\section{Open Science Journal}

Research Article

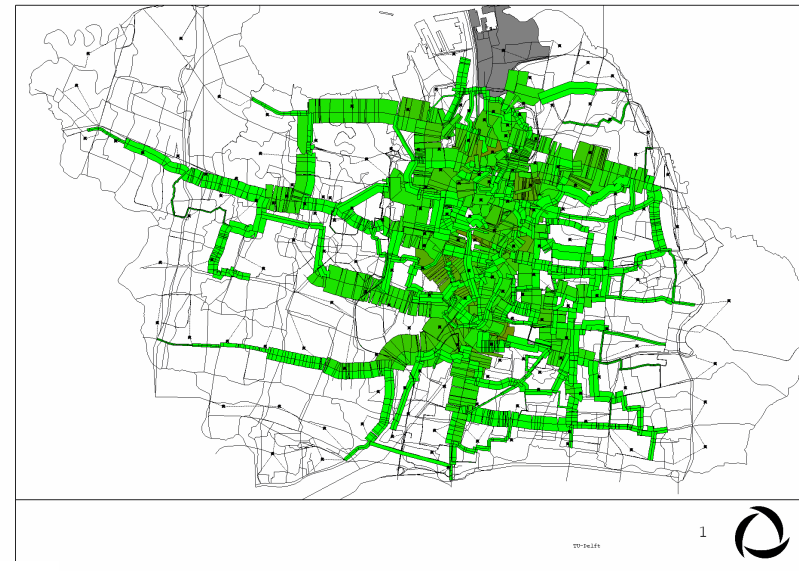

$4 \mathrm{a}$

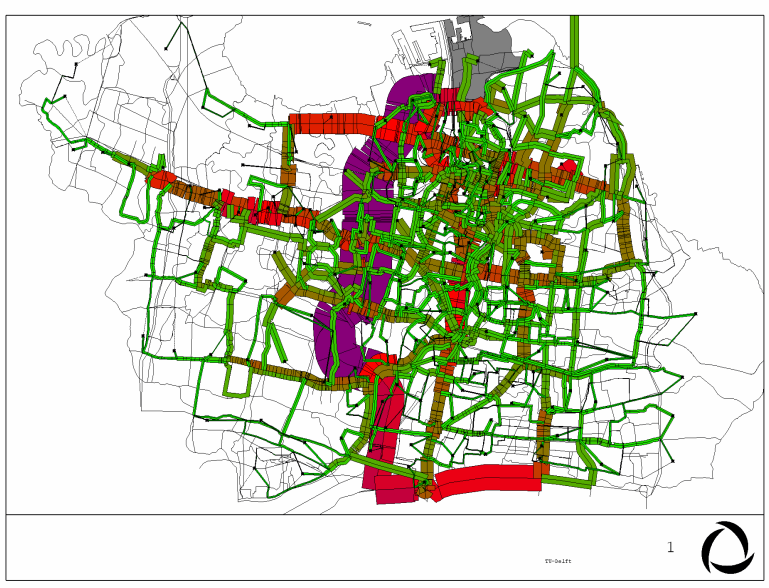

$4 c$

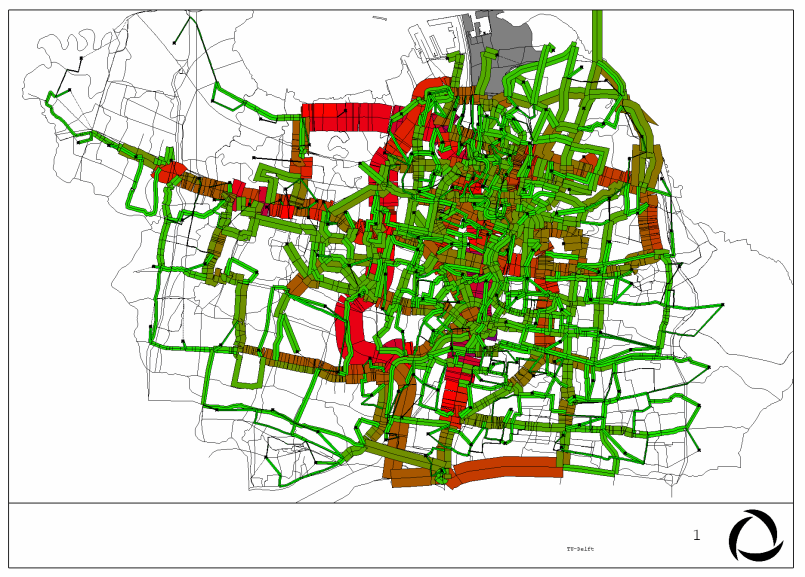

$4 \mathrm{e}$

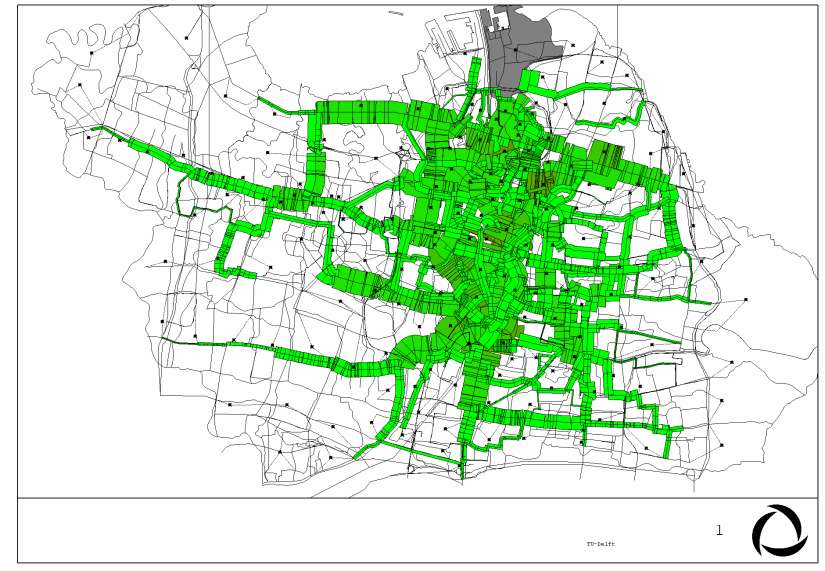

$4 \mathrm{~b}$

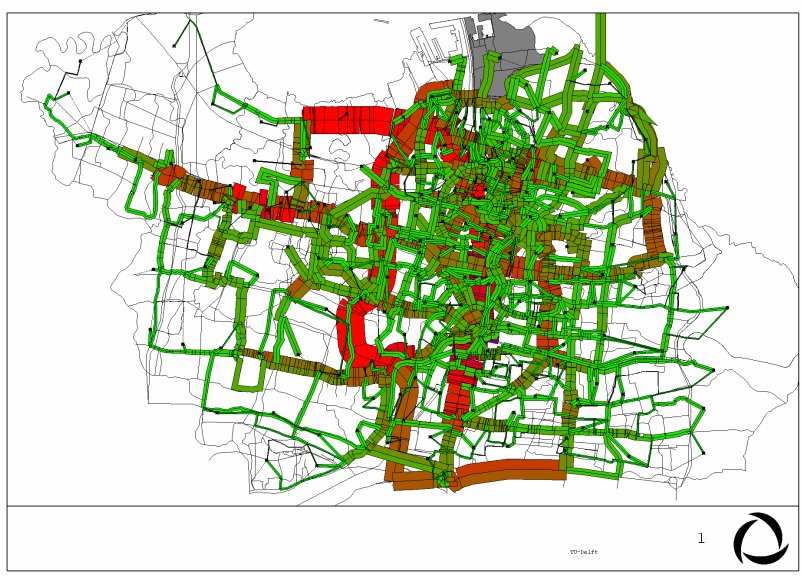

$4 d$

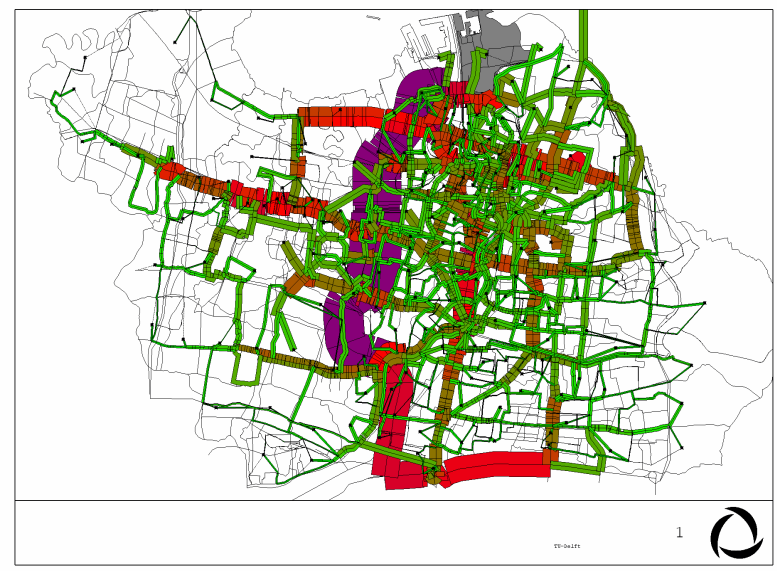

$4 \mathrm{f}$

Fig. 4 Differences in load of public transport (PT) (4a and 4b), motorcycle (MC) (4c and 4d), and car (4e and 4f) in a weekday and at the weekend. 


\section{Conclusions and Recommendation}

The objective of this paper was to explain important issues associated with the estimation of the value of travel time savings for travelers living in the suburbs for weekday and weekend trips, and to explain the application of the value of time on the change in modal split for cities in developing countries.

Comparative analysis was carried out in order to assess the value of time based on revealed and stated preference survey and GDP of the City of Surabaya by employing mode choice and income approach respectively.

We applied a simple model, the linear regression model, based on a preference survey. The value of travel time was assessed as a regression-fit model based on travel time and travel cost for each vehicle class.

In summary, we note that the value of time for weekday trips has more significant value than other trips. Private vehicles, particularly motorcycles, have the highest value of time savings. The number of car drivers at weekends is more than those in the weekday due to reduction of value of time. In order to increase the value time savings of public transport passengers in weekdays, public transport should be operated at higher frequency. An increase in the value of travel time savings means an increase in willingness to use public transport. The improvement of public transport system should be undertaken to accommodate the increase in travel time savings of public transport passengers.

Further scope for research is to consider the value of time savings for other large cities in developing countries. It is important to assess individual-based parameters by employing MMNL model in order to predict the advantages of certain transport developments.

\section{References}

[1] Henser, D.A. (1977). Value of Business Travel Time. Pergamon, Oxford.

[2] Wardman. (1998). The Value of Travel Time - A Review of British Experience. Journal of Transport Economics and Policy, 32(3), 285-316.

[3] Mackie, P.J., Jara-Diaz, S., Fowkes, A.S. (2001). The Value of Travel Time Savings in Evaluation. Transport Research Part E. 37 (2-3), 91-106.

[4] Tseng, Y, Verhoef, E., T. (2008). Value of Time by Time of Day: A Stated-Preference Study. Transportation Research Part B, 42, 607-618.

[5] Jara-Diaz, S Munizaga, M. A., Greeven, P., Guerra, R., Axhausen, K. (2008). Estimating the Value of Leisure from a Time Allocation Model. Transportation Research Part B, 42, 946-957.

[6] Department of Planning and Development of Surabaya. (2007). Master Plan of Surabaya City. Technical Report Surabaya, Indonesia. 